\title{
Processing and Electromagnetic Shielding Properties of Multifunctional Metal Composite Knitted Fabric used as Socks
}

\author{
Zhicai YU ${ }^{1,2, a}$, Hualing $\mathrm{HE}^{1,2, \mathrm{~b}^{*}}$, Yutong $\mathrm{HAN}^{1}$, Fei LIN ${ }^{1}$, Xiaori YANG ${ }^{1}$, \\ Shun $\mathrm{ZHU}^{1}$, Nan WANG ${ }^{1}$ and Jia-Horng $\mathrm{LIN}^{3,4,5}$ \\ ${ }^{1}$ School of Chemical Engineering, Eastern Liaoning University, Dandong, 118003, China \\ ${ }^{2}$ Liaoning Key Laboratory of Functional Textile Materials, Eastern Liaoning University, Dandong, \\ 118003, China \\ ${ }^{3}$ Laboratory of Fiber Application and Manufacturing, Department of Fiber and Composite Materials, \\ Feng Chia University, Taichung 40724, Taiwan \\ ${ }^{4}$ School of Chinese Medicine, China Medical University, Taichung 40402, Taiwan \\ ${ }^{5}$ Department of Fashion Design, Asia University, Taichung 41354, Taiwan \\ âEmail:yuzhicaicai@163.com, ${ }^{b * E m a i l: ~ h e h u a l i n g h e @ 126 . c o m ~}$
}

\begin{abstract}
In this research, a type of bamboo charcoal polyester (BC-PET)/antibacterial nylon(AN)/stainless steel wire (SSW) metal composite yarn was prepared with a hollow spindle spinning machine, which using the SSW as the core material, the BC-PET and AN as the outer and inner wrapped yarns, respectively. The wrapping numbers was set at 8.0 turns $/ \mathrm{cm}$ for the produced metal composite yarns. Furthermore, a type of plated knitted fabric was designed and produced by using the automatic jacquard knitting machine. The plated knitted fabric presents the BC-PET/AN/SSW metal composite yarn on the knitted fabric face and the crisscross-section polyester (CSP) on the knit back. The effect of lamination numbers and angles on the electromagnetic shielding effectiveness (EMSE) were discussed in this study. EMSE measurement showed that the lamination angles will influence the EMSE, but not affect the air permeability. Finally, a novel EM shielding socks was designed with the produced plated knitted fabric. Finally, the performance of thermal resistance and evaporation resistance was also test usingThe sweating guarded hot plate apparatus.
\end{abstract}

Keywords: EM shielding sock; metal composite yarns; plated knitted fabric; lamination numbers; lamination angles

\section{Introduction}

With the development of science and technology, more and more electronics products are present in our daily life. Therefore, it will cause various electromagnetic (EM) wave reveal and pollute the human living space. Various forms of electromagnetic waves not only cause electrical and electronic malfunctions but also link to serious health problems, such

\footnotetext{
*Corresponding author: hehualinghe@126.com
} 
as leukemia, brain tumors, Alzheimer's disease, sleeping problems, and depression. Hence, research and development of EM shielding products is becoming very necessary. Compared to other EM shielding materials, EM shielding fabric could not only meet the need of the people's daily life but also could protect the human body from EM radiation. Thus, the EM shielding fabric is more close to people's life ${ }^{[1-3]}$.

At present, the EM shielding fabric was obtained mainly through metal coating or plating on the surface of the fiber. However, this type of EM shielding textile has some fatal flaws, such as poor resisting abrasion, bad resisting washing, single function property et al. The stainless steel wire (SSW) had been provided that has great EM shielding property. However, there are processing difficulties associated with weaving or knitting of bare metallic wires ${ }^{[4]}$. Hence, the metal composite yarns composing SSW was often used to produce EM shielding fabrics. At present, although many kinds of EM shielding fabrics had been produced to shielding waves, the multifunctional EM shielding socks have not been produced and researched. For the purpose of this study, a novel of bamboo charcoal polyester $(\mathrm{BC}-\mathrm{PET}) /$ antibacterial nylon $(\mathrm{AN}) /$ with the wrapped number of $8.0 \mathrm{turns} / \mathrm{cm}$ were produced with SSW as the core yarn, AN yarn as the inner wrapped yarn, and BC-PET as outer wrapped yarn by using a hollow spindle spinning machine. Then, a type of plated knitted fabric was designed and produced to multifunctional EM shielding socks using the metal composite yarns、 crisscross-section polyester, and spandex on the automatic jacquard knitting machine. The EM shielding socks not only processing EM behavior but also shows antibacterial and health care property. In this paper, we mainly study the effect of lamination number and angles on the air permeability and EM shielding properties for the produced plated EM shielding knitted fabric used as socks.

\section{Materials and Methods}

\subsection{Production of Metal Composite Yarns and Plated Knitted Fabrics}

The BC-PET/AN/SSW metal hybrid yarns were produced on a hollow spindle spinning machine (DH CR -20) with a wrapped number of 8.0 turns $/ \mathrm{cm}$. To make the produce EM shielding socks have great water transport ability and elastic properties, the 25 denier spandex was back plated with CSP yarn and the produced metal composite yarns as the front face of plated knitted fabric and then the EM shielding socks was fabricated on automatic jacquard knitting machine. Finally, the stocking toe was tailored by using a sewing machine (DK-D-318-8). Figure 1 shows the produced EM shielding socks and automatic jacquard footwear sock machine. 


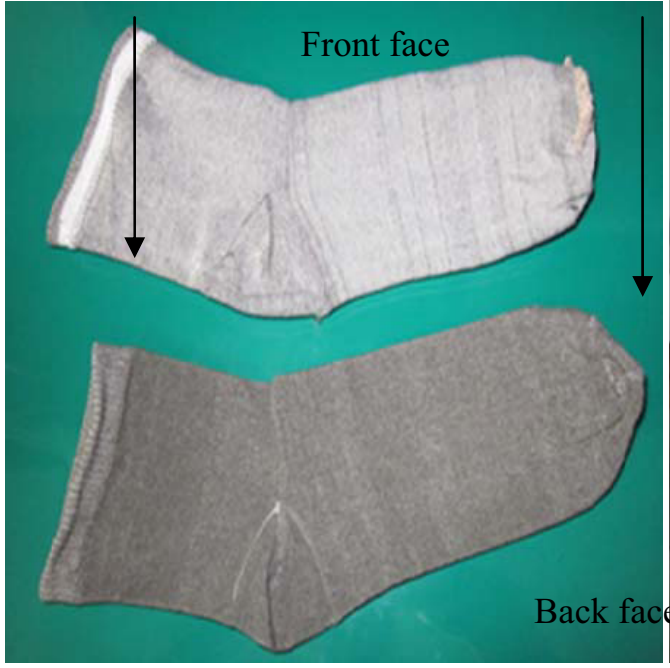

(a) EM shielding socks

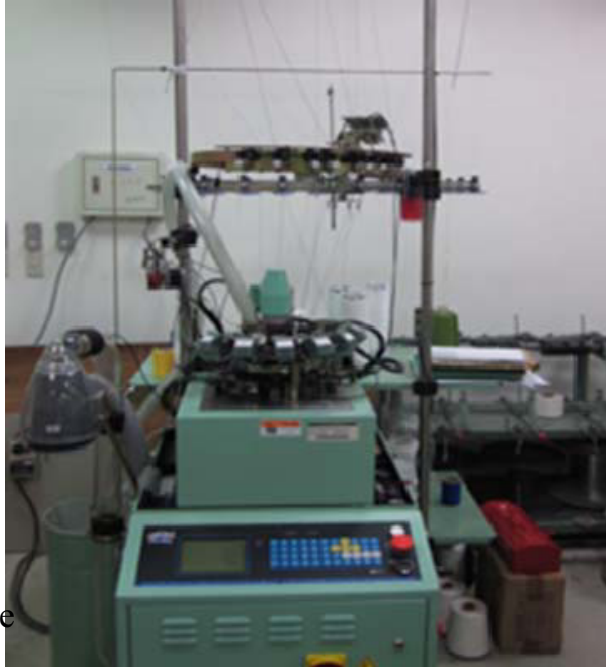

(b) Footwear machine

Fig. 1. The illustration of EM shielding sock (a) and footwear machine (b)

\subsection{EMSE and Air Permeability Measurement}

A coaxial transmission line method specified in ASTM D4935-99 was used to test the EMSE of the metal composite knitted fabrics. The EM shielding device includes a network analyser and a test fixture as shown in Figure 2. In this study, the scan frequency varied from $300 \mathrm{kHz}$ to $3 \mathrm{GHz}$. To investigate the effect of lamination numbers and angles of fabricated plated knitted fabrics on the EM shielding and air permeability, the lamination method described by Yu et al. was used .

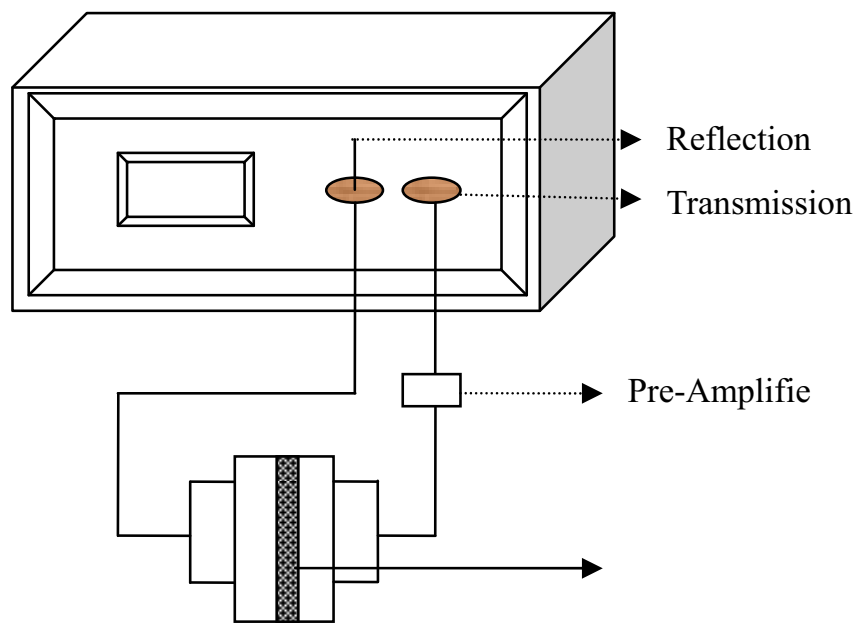

Fig. 2. EMSE test set up as per ASTM D4935 standard. 


\section{Results and Discussion}

\subsection{Effect of Lamination Numbers and Angles on the EMSE of the Plated} Knitted Fabrics Used as Sock.

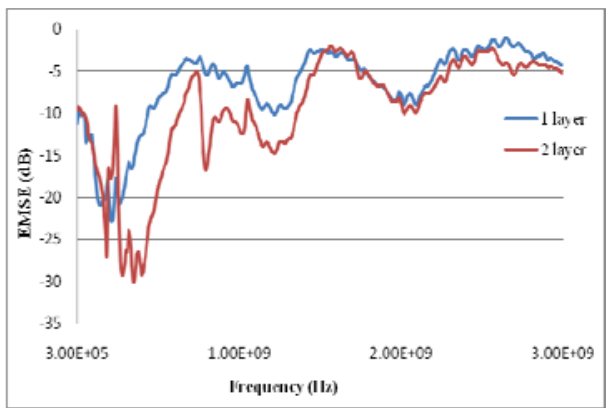

(a)

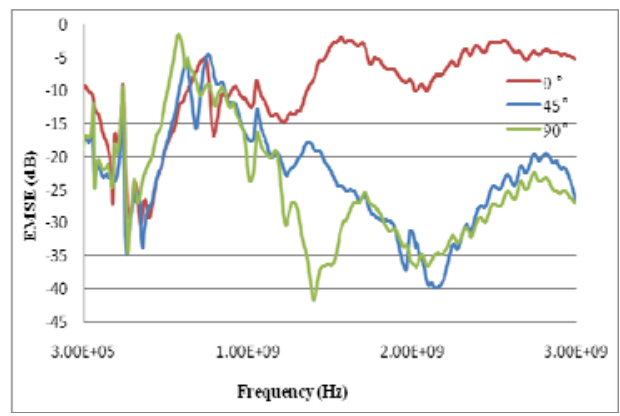

(b)

Fig. 3. EMSE of produced plated EM shielding fabrics used as socks at different layers (a) and lamination angles (b).

In this research, the EM shielding sock was produced with the single-layer produced plated knitted fabrics. Figure 3 presents the EMSE levels of produced sock. From Figure 3, it was found that the EM shielding sock shows a certain EM shielding property in the frequency range of $3000 \mathrm{KHz}$ to $3 \mathrm{GHz}$. This results was attributed to the great EM reflect behavior of SSW. This EM shielding sock wear in our daily life. It could not provide the human body from undesirable EM radiation but could also provide health care function. However, it can be seen that the EMSE value was low $10 \mathrm{~dB}$ for the socks. To increase the EMSE, the effect of lamination numbers and angles of produced plated knitted fabrics used as sock was investigated in this study. From Figure 3, it was found that compared to single layer, two layers knitted fabrics will not obvious enhance the EMSE values when the two layers with $0^{\circ}$ lamination angles. However, the EMSE values will increase obviously when varying the lamination angles. This was due to changing the lamination angles will alter the conductive metal net. Hence, the EM waves will not easily penetrate the EM shielding knitted fabrics .In this study, the EMSE will research up to $-5 \mathrm{~dB}$ in the frequency range of $3000 \mathrm{KHz}$ to $3 \mathrm{GHz}$ for the fabricated EM shielding socks.

\subsection{Effect of Lamination Numbers and Angles on air Permeability of the Plated}

\section{Knitted Fabrics Used as Sock.}
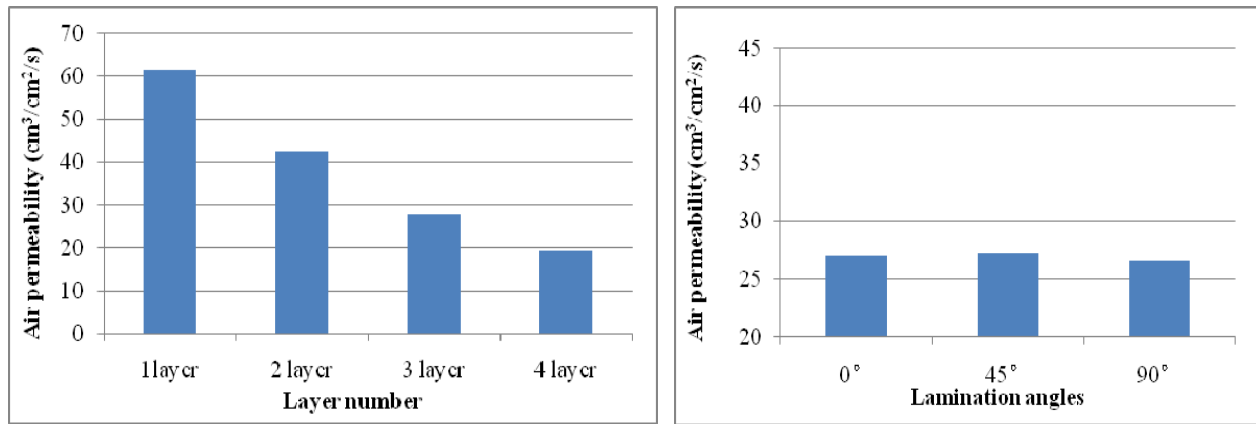

Fig. 4. Effect of lamination numbers and angles on Air permeability of the plated knitted fabric(Two layer). 
Figure 4 present the air permeability of multi-layer fabrics with different lamination angles. Figure 2 shows that the increasing the lamination layers will decrease the air permeability . However, it should be not that the lamination angles will not influence the air permeability for the two-layer plated knitted fabrics. It means that varying the lamination angles will increase the EMSE, but not influence the air permeability. Hence, varying the lamination angles is a great method to increase the EMSE for the fabricated plated fabric.

\subsection{The Performance of Thermal Resistance and Evaporation Resistance}

The sweating guarded hot plate apparatus was used to simulate the heat and moisture transfer process that occurs between the skin and fabric according to the ISO 11092 standard under a plate surface temperature of $35^{\circ} \mathrm{C}$. In this study, we used the sweating guarded hot plate apparatus to test the thermal comfort sensation of wearers. Figure 6 shows the schematic diagram of the test apparatus. The sweating hot plate could be used to simulate the transfer process of the moisture and heat between the skin and fabric. The samples were cut into $500 \mathrm{~mm} \times 500 \mathrm{~mm}$ squares and were placed on the surface of the hot

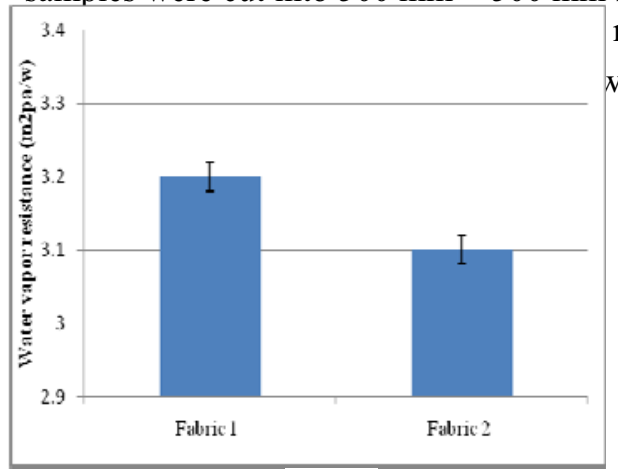

(a)

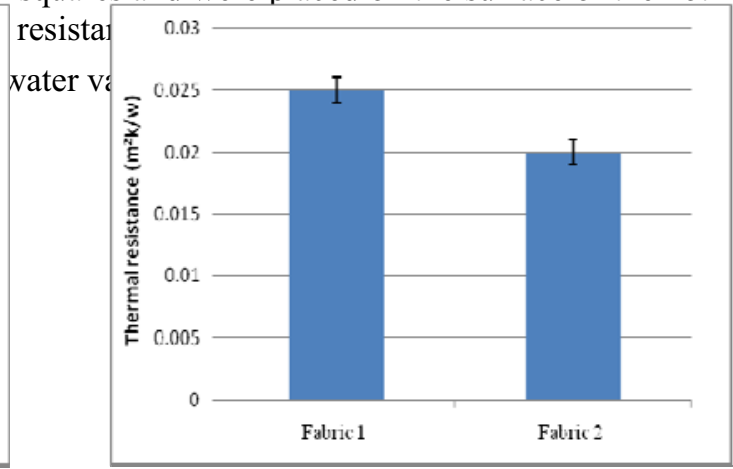

(b)

Fig. 5. The thermal resistance (a) and water vapor resistance (b) performance

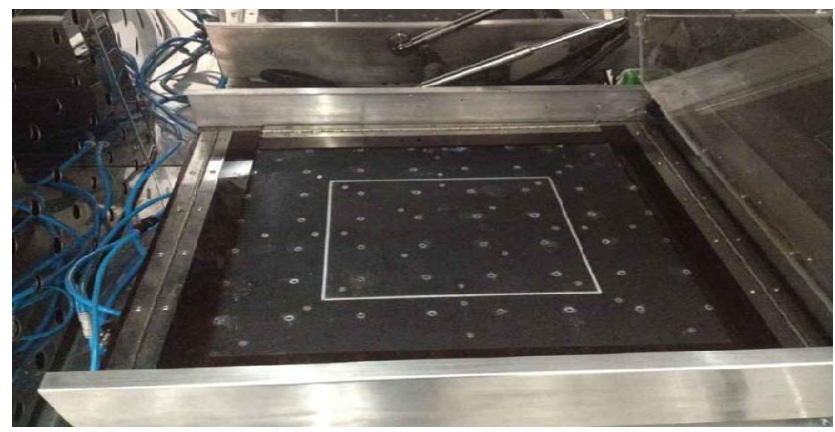

Fig.6 . Sweating guarded hot plate apparatus

In this study, the BC-PET/AN/SSW and PET/AN/SSW metal hybrid yarns was used to fabricate the knitted fabric, respectively. From the Figure 6, it can be seen that the present of BC-PET yarns could obvisouly increase the thermal resistance of the fabricated fabrics. However, it could not affact the water vapour resistance. Hence, used the BC-PET yarns could not increase the health care property but also offer the keep warm property. 


\section{Summary}

In this study, the metal composite plated-knitted fabrics and socks have been produced. This type of novel sock could be wear in our daily life and protect the human body from EM hazard. To increase the wear comfort, the CSP and prepared BC-PET/AN/SSW metal composite yarns was used as the back and front face of the EM shielding socks. The EMSE will research up to $-5 \mathrm{~dB}$ in the frequency range of $3000 \mathrm{KHz}$ to $3 \mathrm{GHz}$ for the fabricated EM shielding socks. Moreover, increasing the layers could not increase the EMSE for the plated knitted fabrics. However, varying the lamination angle could obviously increase the EMSE. Finally, it was also found that varying the lamination angles would not influence the air permeability. Further studies will be carried out to investigate the antibacterial, healthcare function, and wear comfort.

\section{Acknowledgements}

This research was supported by financial support from the youth fund project of Eastern Liaoning University (2015QN004; 2015QN003 ) and Education Department Funds of Liaoning Province (No. L2015188). This research was also supported by the project of the graduate innovation and enterprise program of Liaoning Province.

\section{References}

1. Z. C.Yu, J.F.Zhang, C.W. Lou and J.H. Lin, Textile Research Journal. 85(2015),p.188-199.

2. Z. C.Yu, J.F.Zhang, C.W. Lou, H. L. He, A.P. Chen and J.H. Lin,AUTEX Research Journal. 15(2015) p.60-66.

3. Rajendrakumar K, Thilagavathi G,Journal of Industrial Textile. 42 (2012), p.400-410.

4. Z. C.Yu, H. L. He, Y. H. Lu, J.F.Zhang, C.W. Lou, A.P. Chen and J.H. Lin,FIBRES \& TEXTILES in Eastern Europe .23(2015), p.78-83. 